\title{
Subjective Well-being and Partnership Dynamics: Are Same-Sex Relationships Different?
}

\author{
Shuai Chen ${ }^{1} \cdot$ Jan C. van Ours ${ }^{2,3,4,5,6}$ \\ Published online: 1 November 2018 \\ (C) The Author(s) 2018
}

\begin{abstract}
We analyze Dutch panel data to investigate whether partnership has a causal effect on subjective well-being. As in previous studies, we find that, on average, being in a partnership improves well-being. Well-being gains of marriage are larger than those of cohabitation. The well-being effects of partnership formation and disruption are symmetric. We also find that marriage improves well-being for both younger and older cohorts, whereas cohabitation benefits only the younger cohort. Our main contribution to the literature is on well-being effects of same-sex partnerships. We find that these effects are homogeneous to sexual orientation. Gender differences exist in the well-being effects of same-sex partnerships: females are happier cohabiting, whereas marriage has a stronger well-being effect on males.
\end{abstract}

Keywords Subjective well-being $\cdot$ Happiness $\cdot$ Marriage $\cdot$ Cohabitation $\cdot$ Same-sex relationships

Electronic supplementary material The online version of this article (https://doi.org/10.1007/s13524-0180725-0) contains supplementary material, which is available to authorized users.

Shuai Chen

s.chen_2@tilburguniversity.edu

1 Department of Economics and CentER, Tilburg University, P.O. Box 90153, Room P2.115, 5000 LE Tilburg, the Netherlands

2 Erasmus School of Economics, Postbus 1738, Room H12-10, 3000 DR Rotterdam, the Netherlands

3 Department of Economics, University of Melbourne, Melbourne, Australia

4 Tinbergen Institute, Amsterdam, the Netherlands

5 EHERO, Rotterdam, the Netherlands

6 CEPR, London, UK 


\section{Introduction}

In the past decades, numerous studies in economics, sociology, and demography emerged on the relationship between partnership and well-being or happiness. ${ }^{1}$ This literature has predominantly asserted a positive association between marriage and wellbeing (Carr and Springer 2010; Diener and Suh 1997; Gove and Shin 1989; Kalmijn 2017; Umberson and Karas Montez 2010; Waite and Gallagher 2000). Recently, a few studies examined whether such a positive relationship exists between cohabitation and well-being, finding mixed results (Brown et al. 2005; Hansen et al. 2007; Kamp Dush 2013; Kohn and Averett 2014a; Musick and Bumpass 2012; Soons and Kalmijn 2009; Soons et al. 2009; Wright and Brown 2017).

The positive association between partnership and well-being could originate from a causal effect of partnership on happiness. However, the positive association could also be due to selection: happier individuals are more likely to enter a partnership (Johnson and Wu 2002; Kalmijn 2017; Kim and McKenry 2002; Sandberg-Thoma and Kamp Dush 2014; Stutzer and Frey 2006; Waldron et al. 1996; Wilson and Oswald 2005). ${ }^{2}$ Four nonexclusive explanations can be offered for the causal effect. First, partnered individuals may gain from production complementarities - that is, specialization and division of labor (Becker 1974, 1981; Stutzer and Frey 2006). Second, partnership may offer consumption and investment complementarities (Lundberg and Pollak 2015; Stevenson and Wolfers 2007). Couples may benefit from economies of scale by pooling resources, jointly consuming public goods and investing in children, and sharing leisure activities (Killewald 2013; Waite and Gallagher 2000). Third, a partnership may strengthen and expand social relationships. Partnered individuals not only receive intimacy, commitment, and care from their partner but also obtain material and emotional support from the family, relatives, and friends of their partner (Kamp Dush and Amato 2005; Ross 1995). Finally, a partnership may introduce social control and mutual supervision salutary to the couple's well-being. The norms in a partnership and the daily supervision by the partner reduce possible risky behavior (Duncan et al. 2006; Fleming et al. 2010; Monden et al. 2003; Umberson 1992).

We investigate the well-being effects of partnership dynamics in the Netherlands, which has witnessed notable demographic changes in the past decades. In terms of partnership formation, cohabitation has become more popular at the expense of marriage. For example, by age 30,34\% of women born in the 1950s had been or were still cohabiting, and $78 \%$ had been or were still married. Among women born in the 1970 s, these percentages switched by age 30 to $69 \%$ for cohabitation and $45 \%$ for marriage. In 1998, there were approximately 3.4 million married couples, 0.6 million cohabiting households, and 2.2 million single households. In 2016, the number of married couples decreased to 3.3 million, and the numbers of cohabiting couples and single households increased to 1.0 and 2.9 million, respectively. Furthermore, fewer cohabiting couples made a transition into marriage. For instance, for cohabiting women aged 20-24, the probability of being married within three years after the start of cohabitation clearly

\footnotetext{
${ }^{1}$ The literature regards subjective well-being as a substitute for happiness (Diener et al. 2009). We use the two terms interchangeably.

${ }^{2}$ There could be adverse selection, too, if individuals with inferior well-being are more likely to seek actively for partnership because of the protection it offers.
} 
dropped. For those starting to cohabit in 1970-1974, this probability was $58 \%$; for those starting to cohabit in 1980-1984, the probability reduced to $37 \%$; and for the 1990-1994 cohort, the probability further fell to $27 \%$. In the meantime, divorce rates have risen. In 1970, approximately $0.3 \%$ of all marriages dissolved; in 2014, this rate was approximately $1 \%$ (Statistics Netherlands n.d.).

Our study exploits panel data on partnerships and subjective well-being collected in the Netherlands over the period 2008-2013. Our data allow us to distinguish between marriage and cohabitation and between different-sex and same-sex relationships. Couples may invest different levels of tangible and intangible capital (Michael 2004) in marriage and cohabitation (Nock 1995; Stanley et al. 2004), and thus the subjective well-being derived from cohabitation and marriage may be different. In addition, partnership effects on well-being can differ between different-sex and same-sex couples for two reasons. First, same-sex couples may be less likely to obtain social connections and support for their partnership. Although same-sex marriages were legalized in 2001 in the Netherlands, they may still not be completely accepted by these couples' family, relatives, neighbors, or even employers and fellow employees (Badgett 1995; Berg and Lien 2002; Carpenter 2007; Clain and Leppel 2001; Elmslie and Tebaldi 2007; Patacchini et al. 2015). As soon as same-sex partners start cohabiting or get married, their sexual orientation is likely to be disclosed to the public, including their employers and coworkers (Plug and Berkhout 2004). Possible discrimination and unfriendly behavior will directly harm their well-being (Hatzenbuehler et al. 2010; Huebner et al. 2004; Mays and Cochran 2001; McCabe et al. 2010; Meyer 2003). Second, pressure from family and society may force sexual minorities to adjust their behavior, which in turn affects their well-being. For instance, they may refuse to openly enter a partnership, be less likely to adopt a child, shy away from prejudiced occupations (Plug et al. 2014), and bear a higher risk of partnership dissolution. According to Statistics Netherlands (n.d.), more than $30 \%$ of female same-sex couples who married in 2005 had divorced by 2015 . The corresponding percentages for male same-sex and differentsex couples are $15 \%$ and $18 \%$, respectively. ${ }^{3}$ Because of the heterogeneity of their partnership formation and stability, same-sex and different-sex couples may differ in the effect of marital partnership on well-being. The issues of the well-being and marital partnership of same-sex couples are largely unexplored in the literature.

Previous studies have investigated differences in well-being effects from marriage and cohabitation but neglected potential heterogeneity of sexual orientation. To the best of our knowledge, we are the first to investigate whether same-sex and different-sex partnerships differ in their effect on subjective well-being. Being the first country to implement the same-sex marriage law, the Netherlands bears the longest duration and relatively mature evolution of same-sex marriages. Thus, its relevant data are

\footnotetext{
3 The differences in divorce risks between same-sex partnerships and different-sex partnerships may be attributed to different factors. Same-sex couples are less likely to have children in their household, and children and the investment in children usually help stabilize a partnership (Andersson et al. 2006). Another risk factor of divorce for same-sex couples is a big age difference (Noack et al. 2005). As in the Netherlands, same-sex marriages of women in Norway and Sweden have the highest divorce risks (Andersson et al. 2006; Noack et al. 2005). The reasons for gender differences in divorce risks of same-sex partnerships are not clearly addressed in the literature. One explanation may be different levels of minority stress (Meyer 2003). Moreover, the so-called open relationship or open marriage may prevail more in same-sex couples of men and less so in same-sex couples of women compared with different-sex couples.
} 
considerably appropriate for our specific research topic. Moreover, the Netherlands is a country with a highly tolerant attitude to same-sex, bisexual, and transgender (LGBT) individuals or sexual minorities. For example, in the Eurobarometer 2015, $91 \%$ of the Dutch respondents agreed with the statement that "same-sex marriages should be allowed throughout Europe," whereas the average across the 28 EU countries was $61 \%$ (European Commission 2015).

We also study whether partnership effects on subjective well-being are age cohortspecific. Older adults are more likely to be unmarried by remaining cohabiting or dating without making a formal commitment (Brown and Shinohara 2013; Brown et al. 2006; Calasanti and Kiecolt 2007; Cooney and Dunne 2001; Sassler 2010) and by increasingly divorcing (Brown and Lin 2012; Kennedy and Ruggles 2014). Later in life, cohabitation operates as a long-term alternative to marriage. Therefore, the positive well-being effect of cohabitation may be comparable with that of marriage for the older cohort (Brown et al. 2012; King and Scott 2005; Vespa 2012; Wright and Brown 2017). However, older adults may also prefer to protect the wealth they have accumulated over their lifetime rather than pool resources with their partner (Brown et al. 2012). Cohabitation allows them to retain financial and economic autonomy (Brown et al. 2016; Chevan 1996; Hatch 1995). Moreover, older adults may be less willing to provide caregiving to a partner at later stages of their life. Cohabitation does not explicitly expect this kind of responsibility as marriage does (Talbott 1998). Therefore, the positive well-being effect of cohabitation could be smaller than that of marriage for older adults. Our study adds to the literature on whether the well-being impact of cohabitation is similar to that of marriage for different age cohorts.

Finally, we analyze whether the well-being effects are symmetric for partnership formation and partnership dissolution. Symmetry implies that partnership formation and partnership dissolution have similar magnitudes but opposite signs. Intuitively, at the beginning of a partnership, a couple is enjoying intimacy and mutual trust (Michael 2004), and thus partnership formation has a positive effect on well-being (Lucas and Clark 2006; Lucas et al. 2003). However, as time goes by, a partnership may be confronted with difficulties and face a breakup. Therefore, partnership dissolution may have a negative effect on the well-being of the individuals involved. Only a handful of studies have examined the well-being gain produced by partnership formation and the well-being loss resulting from a partnership dissolution simultaneously, typically finding strong effects of partnership dissolution (Kalmijn 2017; Simon 2002; Strohschein et al. 2005; Williams and Umberson 2004). However, these studies have not rigorously tested whether partnership formation and dissolution have symmetric effects on well-being. Hence, our study is one of the first to systematically compare every entry-exit pair among different partnership transitions, examining whether the effects within every pair are symmetric.

Our contribution to the literature on partnership and well-being is threefold. First, we establish the causal effects of marriage and cohabitation on subjective well-being. Second, we systematically test the symmetry of partnership formation and dissolution. Third, and most important, we examine well-being effects of same-sex partnerships. We confirm the results from previous studies that the well-being gains of marriage are larger than those of cohabitation. We find that these effects are homogeneous to sexual orientation. We also find gender differences in the well-being effects of same-sex partnerships: females are happier cohabiting, whereas marriage has a stronger well-being effect on males. 


\section{Conceptual Background}

\section{Theoretical Framework}

Traditionally two competing models explain the mechanisms through which partnership formation and partnership dissolution affect well-being: the long-term resource accumulation model and the short-term crisis adaptation model.

The long-term resource accumulation model argues that the well-being gains of partnership formation accumulate over time rather than manifest immediately. As a partnership proceeds, the couple invests more resources in terms of shared tangible property (income, real estate, combined families, and mutual friends) and intangible capital (intimacy, trust, commitment, and family responsibilities) (Kamp Dush and Amato 2005; Rhoades et al. 2011; Rusbult 1980). Thus, partnership ties become stronger over time, and the positive well-being effect increases with partnership duration (Kalmijn 2017; Waite and Gallagher 2000). Likewise, well-being losses of partnership disruption will materialize gradually. Additionally, the loss of the gradually accrued investment in the previous partnership makes it difficult for divorcees' well-being to recover (Stanley et al. 2006). Simpson (1987) showed that after breaking up a longer partnership, people feel higher levels of distress over a longer period than individuals who break up after a short partnership. The resource model has some variants - such as the investment model (Rusbult 1980), role theory (Pearlin 1999), and chronic strain theory (Amato 2000) - all of which share the similar idea of gradual wellbeing promotion and deterioration in the long run during partnership formation and dissolution, respectively.

The short-term crisis adaption model asserts that the stress around partnership disruption is only temporary, and divorcees are able to recover or adjust quickly. Thus, the initial negative well-being effect will fade with time (Acock and Demo 1994; Booth and Amato 1991; Pearlin 2009; Stroebe et al. 2007). Moreover, Wheaton (1990) claimed that partnership disruption, as a stressful event, actually alleviates the stress of sustaining an unsuitable, low-quality partnership, so the breakup distress is only short-term. Similarly, the positive well-being effect of partnership formation is only temporary. Partnered individuals increase well-being only short term, thereafter adapting back to their original, prepartnership level of well-being determined by stable internal characteristics, such as personality (Anusic et al. 2014; Lucas and Clark 2006; Lucas et al. 2003; Musick and Bumpass 2012; Soons et al. 2009). Other variants of the crisis model include adaptation theory (Diener et al. 2006; Lucas et al. 2003), the stressful-event-as-stress-relief model (Wheaton 1990), and set-point theory (Anusic et al. 2014).

The theory of the second demographic transition (Lesthaeghe 2007) and the ideational perspective (Lesthaeghe and Surkyn 1988) argue that in countries where citizens' physiological and safety needs have been met, society shifts to valuing self-actualization and individual autonomy. If partnerships support this kind of self-actualization and individual autonomy, partners in the union will enjoy the well-being gains; otherwise, partners will not have these well-being gains or may even have well-being declines. Similarly, Finkel et al. (2014) argued that in modern society, young people hold increasingly high expectations and standards of marriage, such as personal growth in the marital union. The newly marrieds will feel disappointed if marriage does not meet their high expectations and standards of marriage; hence, their well-being may not change substantially or may even decline after getting married. 


\section{Gender Differences}

A few studies have explored gender differences in these well-being effects. Men and women seem to be affected in a similar pattern by marital statuses and transitions (Kalmijn 2017; Strohschein et al. 2005; Williams 2003). However, gender differences in the levels of these effects have been found especially for marital dissolution (Simon 2002; Umberson 1992; Williams and Dunne-Bryant 2006). Simon (2002) and Williams and Dunne-Bryant (2006) found that divorce entails a stronger depression for women than for men and a more significant reduction in psychological well-being for women with young children than for their male counterparts. On the contrary, Kalmijn (2017) and Williams and Umberson (2004) found that marital dissolution undermines life satisfaction and self-reported health more for men than for women. Blekesaune (2008) found that divorce elevates more distress for mothers than for fathers. These differences may be attributed to different social roles of men and women in a partnership (Umberson 1992) or simply to different responses to marital transitions between men and women (Simon 2002).

Gender differences exist between marriage and cohabitation as well, although the results are quite mixed. Wright and Brown (2017) concluded that married and cohabiting men enjoy similar well-being gains compared with dating and single men, but they noted no considerable well-being differences among marital statuses for women. However, Brown et al. (2005) found that among middle-aged and older adults, married women have identical depression scores as cohabiting women and men, but their scores are all higher than those of married men. Mernitz and Kamp Dush (2016) found that among young adults, marriage benefits emotional health for both men and women, whereas cohabitation benefits only women, and these gender differences were detected for first unions only. Kamp Dush (2013) found that among parents who experience union disruption, depressive symptoms of previously married mothers - but not cohabiting mothers - return to predivorce levels; and depressive symptoms of previously married fathers increase more than those of cohabiting fathers. Avellar and Smock (2005) concluded that the dissolution of cohabitation entails a moderate decline for men's economic situation but hurts women's economic standing much more intensely.

Cohabitation may have smaller positive effects on well-being than marriage. Because the former is usually regarded as a trial marriage, cohabitants may invest lower levels of tangible and intangible capital (Michael 2004) in their partnership than married couples do (Nock 1995; Soons et al. 2009; Stanley et al. 2004). Cohabitation, as merely a trial marriage, may exert weaker causal protective effects than marriage does in terms of production and consumption complementarities, social connections, and social controls (as discussed earlier). Moreover, cohabitation bears higher disruption rates and lower expectations for future relationship stability than marriage. Therefore, cohabitation dissolution may less intensely affect well-being than marriage dissolution (Blekesaune 2008; Kamp Dush 2013). Recovery from cohabitation disruption may be also faster than recovery from divorce.

\section{Sexual Minorities}

The literature on the well-being effects of different types of partnerships for sexual minorities is limited, and a distinction based on gender is even more rare. According to 
the minority stress theory (Meyer 2003), sexual minorities in a relationship experience stress when interacting with other people, so they respond with coping strategies, including concealing their relationship (Rostosky et al. 2007). The minority stress may shrink the well-being gap between marriage and cohabitation. Nonetheless, it is also possible that only sexual minorities with lower levels of such minority stress select themselves into marriage. This selection will enlarge the well-being gap between marriage and cohabitation.

Empirically, Fingerhut and Maisel (2010) claimed that having a domestic partnership (closer to marriage than to cohabitation legally) alleviates negative effects of stress on life satisfaction for sexual minorities. Riggle et al. (2010) found that sexual minorities in legally recognized relationships report less psychological distress and higher well-being than those in committed relationships and that a similar gap exists between those in committed relationships and singles. Wight et al. (2013) found that sexual minorities in marriage and domestic partnerships have identical levels of psychological distress, which are lower than those of sexual minority singles and higher than those of different-sex married couples. Gorman et al. (2015) discovered that only among different-sex couples do women report significantly different physical health from men; among sexual minorities, gender differences in physical health do not exist.

\section{Methodology Review}

The methodology to establish a relationship between partnership and well-being has evolved as researchers have made efforts to conquer more challenging questions: going from association to causality and accounting for reverse causality. Three types of studies can be distinguished with increasing degrees of complexity of the analysis. The first type uses cross-sectional data, focusing on correlation between partnership and well-being. Gove and Shin (1989), White (1992), Mastekaasa (1995), and Diener and Suh (1997) conducted such an analysis for the United States, Canada, Norway, and multiple countries together, respectively. They confirmed the positive association between subjective well-being and marriage across countries and cultures. Kurdek (1991) and Mastekaasa (1995) showed that cohabitation is also positively correlated with subjective well-being in some countries. None of the studies in this category addressed the issue of causality: that is, they did not distinguish selectivity from causality or consider possible reverse causality.

The second type tries to remove the selection effect whereby happier people are more likely to enter a partnership. The selection effect is due to individual-specific unobserved heterogeneity, such as personality: extroverted people may be both happier and more likely to find a partner. Static fixed-effects studies take into consideration individual time-invariant unobserved heterogeneity (e.g., Averett et al. 2013; Ferreri Carbonell and Frijters 2004; Musick and Bumpass 2012; Stutzer and Frey 2006). Most of these studies found that partnership, including marriage and cohabitation, increases the well-being of individuals who enter a partnership. However, this conclusion is not universal. For instance, Averett et al. (2013) showed that marriage leads to a higher body mass index, to overweight and obesity, and to less exercise. These studies found evidence of a positive selection effect. Chapman and Guven (2016) employed data 
from the United States, the United Kingdom, and Germany and introduced the quality of marriage as an additional explanatory variable. They discovered that the positive effect of marriage on happiness is driven by happy marriages. For couples who are not happily married, marriage has a negative effect on happiness.

The third type of studies focuses on addressing potential reverse causality - that is, a shock to the well-being of an individual leads to a jump of the likelihood of entering a partnership for that individual. Lillard and Panis (1996) employed a simultaneousequation framework using proportional hazards for health and marital separations. The correlation of the errors of the two equations captures the selection effect. They attempted to address reverse causality by introducing instrumental variables in the health equation. Using a similar measure, van den Berg and Gupta (2015) found that men generally enjoy a protection effect of marriage, whereas women benefit from marriage only after childbearing age. Ali and Ajilore (2011) applied propensity score matching to obtain a counterfactual outcome and correct for selection on observable characteristics. Their results showed that marriage indeed reduces risky health behaviors and thus improves well-being. Two studies by Kohn and Averett (2014a, 2014b) assumed sequential reverse causality from current well-being to the partnership choice in the next period. Their first study used a dynamic fixed-effects model with internal instruments advocated by Blundell and Bond (1998) to account for reverse causality. Their second study exploited a random-coefficient mixed logit model to estimate the unobserved heterogeneity associated with both health and relationship choice, enabling them to disentangle the reverse causality due to this unobserved heterogeneity. Both studies found that marriage and cohabitation benefit health similarly.

\section{Data and Statistical Model}

\section{Data}

Our research is based on data from the Longitudinal Internet Studies for the Social Sciences (LISS) panel administered by CentERdata (www.lissdata.nl). The panel is a random sample of households drawn from the Dutch population consisting of more than 6,500 households, more than 10,000 individuals, and 93 monthly waves over the period November 2007-July 2015.

With information of partnered household heads and their marital or cohabiting partner, we identify the sexual orientation of each individual by comparing one's gender with that of his or her partner (see the online appendix, section A, for details). Thus, individuals who were always single during the period of observation are not included in our analysis that includes sexual orientation. ${ }^{4}$ First, we investigate the effect of any partnership on subjective well-being. Then, we study whether marriage has a different effect on subjective well-being than cohabitation. As society has become more

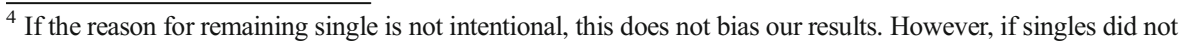
enter a partnership because they would not benefit in terms of well-being, we will overestimate the well-being effects of partnership formation. Nevertheless, it is also possible that these singles have lower well-being levels than people who experienced at least one partnership during the sample period and could have benefited more than average from partnership formation. If that is the case, the well-being effects of partnership will be underestimated in our study.
} 
and more tolerant and people have become increasingly open-minded about partnerships, cohabitation has become considerably popular and a soaring tendency in partnerships, especially in the Netherlands (Latten and Mulder 2013). Given the rapid expansion of cohabitation and its distinction from other marital statuses, it is reasonable to isolate it as a different category.

Our sample contains 27,779 observations, 425 of which are individuals who entered a same-sex relationship. ${ }^{5}$ The sample size of sexual minorities is comparatively small, but it matches the estimated share of sexual minorities in the population (Bakker et al. 2009; Sandfort et al. 2006). In comparison with other studies, our sample of sexual minorities is quite large.

Our indicator of well-being is based on the question, "On the whole, how happy would you say you are?" Responses are provided on an ordinal scale from 0 (totally unhappy) to 10 (totally happy). Panel a of Fig. 1 illustrates the well-being distribution by partnership status. Few respondents reported happiness below 5 on the $0-10$ scale. A higher percentage of individuals in the relatively lower responses of 5, 6, and 7 were nonpartnered, whereas a higher percentage of individuals in the higher responses of 8,9 , and 10 were partnered. Apparently, couples are happier than nonpartnered individuals. Panel b of Fig. 1 further distinguishes marriage from cohabitation in the partnership forms. Compared with married couples, cohabitants account for higher proportions in the happiness response score groups of 5, 6, and 7 but lower proportions in the responses of 8,9 , and 10 . Generally speaking, partners are happier if they are married compared with cohabiting. Nonetheless, the differences between various types of individuals in Fig. 1 are all unconditional and can only be suggestive of a causal effect of partnership on evaluative happiness.

Table 1 gives an overview of average well-being distinguished by marital status and sexual orientation. The last column in the table confirms the findings in Fig. 1. On the 0-10 scale, nonpartnered individuals have an average score of 7.12, and partnered individuals have an average score of 7.71. On average, married couples score 7.76, and cohabitants score 7.56. Comparing the first two columns of Table 1, irrespective of the marital status, sexual minority individuals are happier on average, although the difference is substantial only in the period when they are single. Because the number of observations of singles is rather small, we make no distinction among never married, separated, divorced, and widowed. ${ }^{6}$

The partnership transitions are displayed in Table 2, which shows a persistent stability in partnership status. Among the 6,702 individuals in our sample, only 614 partnership transitions happened over a period of five years. Transitions from cohabitation account for the largest fraction, at more than twice the transition rates from each of the other two marital statuses. Most of the cohabitants broke up rather than entered a

\footnotetext{
5 The definitions and descriptive statistics of the relevant variables in the main models are provided in Tables S1 and S2 in online appendix, section A2.

${ }^{6}$ As shown in Table 1, our sample includes 34 observations of the singlehood period for sexual minorities. Among them, 9 observations are for the divorced phase, and 25 observations are for the never-married period. Of the 801 observations of the singlehood period for the sexual majority, 21 observations are for the phase of separation from a cohabitation, 330 observations are for the period of divorce from marriage, 49 are for a widow phase, and 401 are for the period of being never-married. In addition, we cannot establish sexual orientation of 5,224 observations of singles. The latter group of singles is used only in the first part of our analysis.
} 


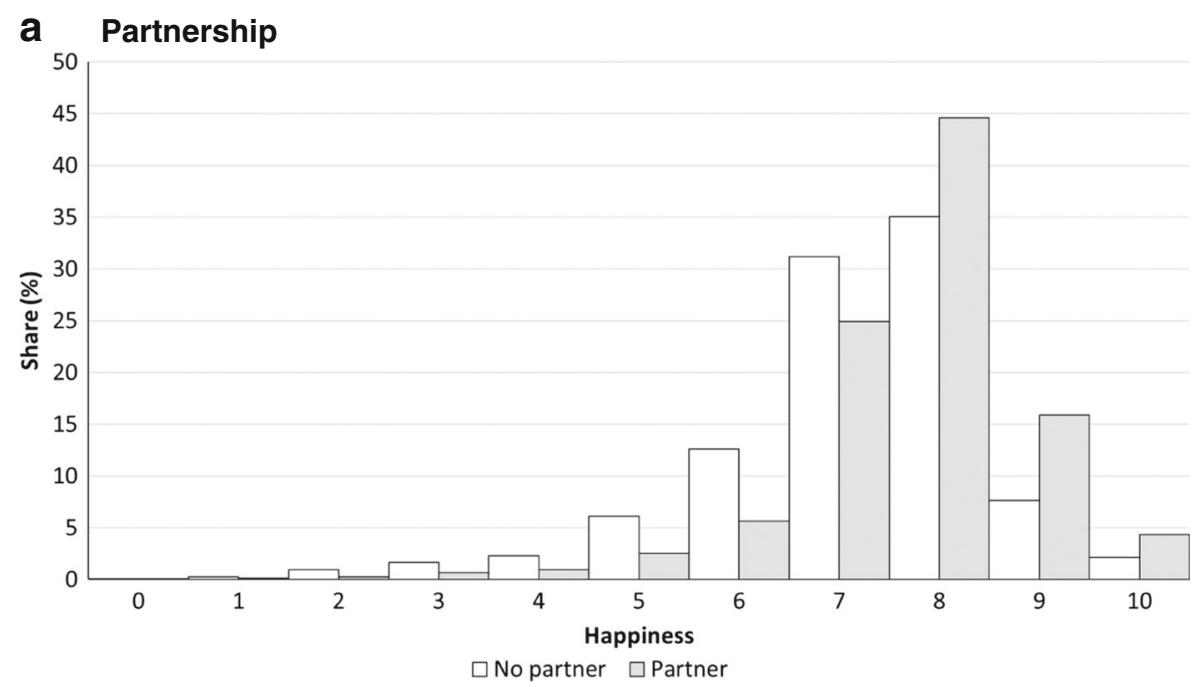

b Marriage and cohabitation

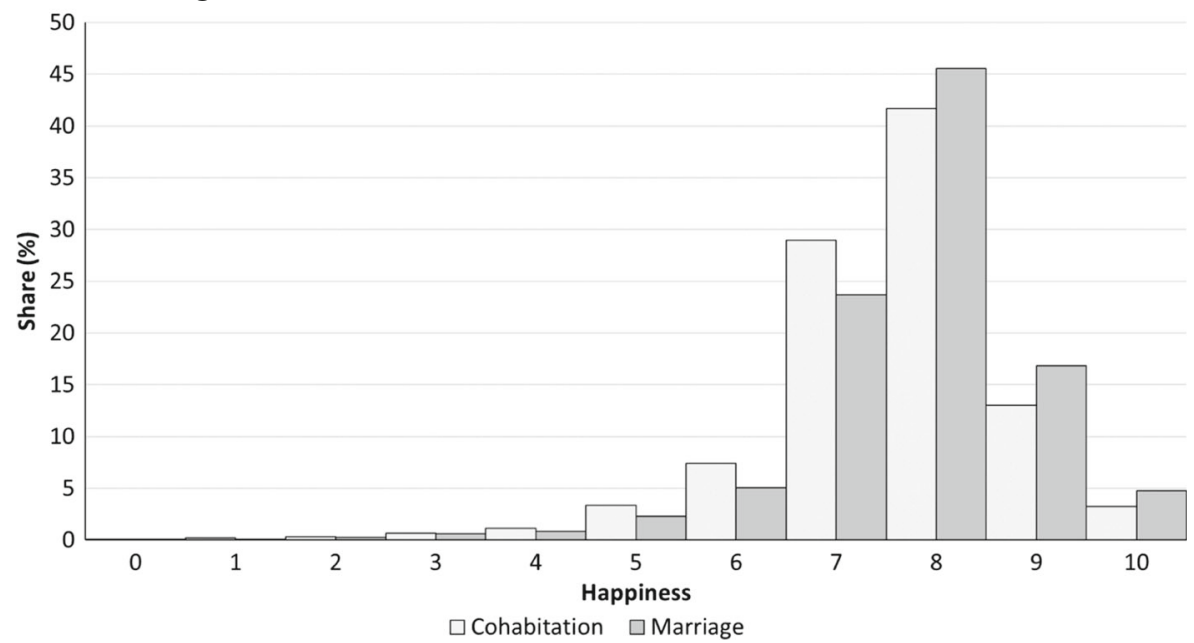

Fig. 1 Well-being and partnership

marriage. More than twice the number of single individuals switched to cohabitation than to marriage. Given the number of observations of these marital statuses in the sample, marriage is considerably more stable compared with cohabitation.

\section{Statistical Model}

Subjective well-being is measured on an ordinal scale from 0 to 10 . To account for time-invariant unobserved personal characteristics, we use a linear fixed-effects model even though the dependent variable in such a model is supposed to be cardinal. As Ferreri Carbonell and Frijters (2004) and Stutzer and Frey (2006) indicated, when 
Table 1 Subjective well-being by marital status and sexual orientation: Averages, with number of observations in parentheses

\begin{tabular}{|c|c|c|c|c|c|c|c|c|}
\hline & \multicolumn{2}{|c|}{ Different Sex } & \multicolumn{2}{|c|}{ Same-Sex } & \multicolumn{2}{|c|}{ Unknown } & \multicolumn{2}{|c|}{ Average } \\
\hline \multicolumn{9}{|l|}{ a. Partnership } \\
\hline No partner & 6.98 & $(801)$ & 7.65 & (34) & 7.14 & $(5,224)$ & 7.12 & $(6,059)$ \\
\hline Partner & 7.73 & $(19,104)$ & 7.76 & $(391)$ & 7.55 & $(2,225)$ & 7.71 & $(21,720)$ \\
\hline \multicolumn{9}{|c|}{ b. Marriage and Cohabitation } \\
\hline Marriage & 7.76 & $(16,043)$ & 7.83 & $(220)$ & 7.81 & (369) & 7.76 & $(16,632)$ \\
\hline Cohabitation & 7.58 & $(3,061)$ & 7.68 & (171) & 7.50 & $(1,856)$ & 7.56 & $(5,088)$ \\
\hline
\end{tabular}

Notes: The category "Unknown" exists because either (1) these individuals have always been single, or (2) if they have ever been partnered, their partners did not participate in the survey, and thus their sexual orientation cannot be identified. See online appendix, section A for details.

analyzing happiness and life satisfaction, the linear fixed-effects model performs as well as the fixed-effects ordered logit model. ${ }^{7}$ Our model is specified as follows:

$$
h_{i t}=p_{i t}^{\prime} \beta_{p}+x_{i t}^{\prime} \beta_{x}+\alpha_{i}+\varepsilon_{i t}
$$

where $i(i=1,2, \ldots, n)$ refers to individuals; $t(t=1,2, \ldots, T)$ represents years; $p$ is either the partnership dummy variable or a dummy vector of different marital statuses, including married and cohabiting, with single as the reference; $h$ denotes well-being measured on a scale from 0 to 10 ; and $\mathbf{x}$ represents the vector of covariates that may be correlated to both partnership and well-being, such as drinking and smoking behavior (Clark and Etilé 2006), body mass index (Clark and Etilé 2011), and physical problems (Graham et al. 2011; Kohn and Averett 2014b), as well as demographic and socioeconomic variables, such as the number of children living at home, whether the respondent is a homeowner, log of personal net monthly income (in euros), whether the respondent holds a college degree, and age cohort dummy variables. Finally, $\alpha_{i}$ represents individual-specific time-invariant effects. The error terms $\varepsilon_{i t}$ are assumed to have a mean of 0 and to be independent of $p_{i}^{\prime}=\left(p_{i 1}^{\prime}, \ldots, p_{i T}^{\prime}\right)$ and $x_{i}^{\prime}=\left(x_{i 1}^{\prime}, \ldots, x_{i T}^{\prime}\right)$. We remove time-invariant unobserved heterogeneity that may affect both partnership and well-being, such as personality, by subtracting individual sample means.

We start our analysis with a pooled cross-section analysis, ignoring individual fixed effects. Conditional on observed characteristics, we estimate the association between partnership and well-being. The association combines the effect of selectivity and the causal effect of partnership on well-being. Then, we introduce individual fixed effects to remove the effect of selectivity, thus establishing a causal effect. In a separate analysis, we also investigate the presence of reverse causality by relating current well-being to future partnership.

\footnotetext{
${ }^{7}$ This is also the case in our analysis. By way of sensitivity analysis, we estimated a fixed-effects ordered logit model and find very similar results.
} 
Table 2 Number of partnership transitions

\begin{tabular}{lllll}
\hline & Married & Cohabiting & Single & Total \\
\hline Married & - & 72 & 61 & 133 \\
Cohabiting & 159 & - & 180 & 339 \\
Single & 44 & 98 & - & 142 \\
Total & 203 & 170 & 241 & 614 \\
\hline
\end{tabular}

Note: Based on 27,779 observations of 6,702 individuals over five years.

\section{Parameter Estimates Subjective Well-being}

\section{Baseline Estimates}

The relevant parameter estimates of our fixed-effects model are displayed in Table 3. The two columns show the partnership effect on happiness for males and females separately. To indicate the importance of considering individual fixed effects, we present ordinary least squares (OLS) parameter estimates in panel a. ${ }^{8}$ There, partnership elevates subjective well-being by 0.60 for men and 0.45 for women, approximately 0.5 points on an 11-point scale. With the fixed-effects setting in panel b, partnership also has a positive effect on happiness, and the difference between males and females is small. Comparing estimates of panels a and $b$ reveals that the OLS estimates are partly driven by positive selection, such that happier individuals are more likely to have a partner. Nevertheless, after we remove this selection effect with the fixed-effects model, there is still a significant increase in well-being related to partnership of approximately 0.25 . So, the effect of partnership on subjective well-being and the selection effect explain approximately $50 \%$ of the positive association between partnership and well-being, respectively. Although well-being is measured on a scale from $0-10$, few respondents report a well-being response lower than 6 , and few individuals report a 10 . In relative terms, an increase of 0.25 over a range of $6-9$ is quite substantial.

In panel c of Table 3, we explore whether partnership effects are different for samesex and different-sex couples. For males, the effect of having a same-sex partner is approximately the same as that of having a different-sex partner. For females, the wellbeing effect of having a same-sex partner is much higher than that of having a differentsex partner. However, like in the case of males, we cannot reject that partnership exerts identical influences on happiness for females in same-sex and different-sex couples.

Panel d of Table 3 shows that marriage makes couples happier than does cohabitation. ${ }^{9}$ We compare the effects of marriage and cohabitation to that of being single. Later herein, we systematically analyze the dynamics or transitions among different partnership statuses. The positive effect of marriage on well-being is stronger for women than for men. The well-being effect of cohabitation is the same for both genders.

\footnotetext{
${ }^{8}$ We also run the OLS models on the subset of people who changed partnership status during the survey period as a robustness check. The results are similar to those in panel a of Table 3 .

${ }^{9}$ We consider panel d in Table 3 as our baseline estimates. Section B in the online appendix presents the parameter estimates of the full baseline model.
} 
Table 3 Parameter estimates for the effects of partnership on subjective well-being: OLS and individual fixed effects

\begin{tabular}{lllll}
\hline & Males & & Females & \\
\hline OLS & & & & \\
$\quad$ a. Partner & $0.60^{* *}$ & $(0.06)$ & $0.45^{* *}$ & $(0.05)$ \\
Individual Fixed Effects & & & & \\
$\quad$ b. Partner & $0.26^{* *}$ & $(0.07)$ & $0.27^{* *}$ & $(0.07)$ \\
$\quad$ c. Partnership by sexual orientation & & & & \\
$\quad$ Different-sex partner $\left(\beta_{d s p}\right)$ & $0.27^{* *}$ & $(0.08)$ & $0.27^{* *}$ & $(0.08)$ \\
$\quad$ Same-sex partner $\left(\beta_{s s p}\right)$ & 0.25 & $(0.31)$ & $0.71^{\dagger}$ & $(0.42)$ \\
$\quad p$ value $\left(\beta_{d s p}=\beta_{s s p}\right)$ & 0.940 & & 0.303 & \\
d. Marriage versus cohabitation & & & & \\
$\quad \begin{array}{l}\text { Marriage }\left(\beta_{m}\right) \\
\quad \text { Cohabitation }\left(\beta_{c}\right)\end{array} \quad 0.33^{* *}$ & $(0.08)$ & $0.39^{* *}$ & $(0.08)$ \\
$\quad p$ value $\left(\beta_{m}=\beta_{c}\right)$ & $0.21^{* *}$ & $(0.07)$ & $0.21^{* *}$ & $(0.07)$ \\
e. Marriage versus cohabitation by sexual orientation & & $.004^{* *}$ & \\
$\quad$ Different-sex marriage $\left(\beta_{d s m}\right)$ & $0.32^{* *}$ & $(0.09)$ & $0.44^{* *}$ & $(0.09)$ \\
$\quad$ Different-sex cohabitation $\left(\beta_{d s c}\right)$ & $0.25^{* *}$ & $(0.08)$ & $0.17^{*}$ & $(0.08)$ \\
$\quad p$ value $\left(\beta_{d s m}=\beta_{d s c}\right)$ & .351 & & $.000^{* *}$ & \\
$\quad$ Same-sex marriage $\left(\beta_{s s m}\right)$ & $0.69^{\dagger}$ & $(0.41)$ & 0.15 & $(0.51)$ \\
$\quad$ Same-sex cohabitation $\left(\beta_{s s c}\right)$ & 0.18 & $(0.32)$ & $0.85^{\dagger}$ & $(0.42)$ \\
$\quad p$ value $\left(\beta_{s m}=\beta_{s c}\right)$ & $.094^{\dagger}$ & & $.058^{\dagger}$ & \\
\hline
\end{tabular}

Note: Panels a, b, and d contain 27,779 observations of 3,088 males and 3,617 females; panels c and e contain 20,330 observations of 2,275 males and 2,526 females. Standard errors are shown in parentheses.

$\dagger p<.10 ; * p<.05 ; * * p<.01$

In panel e of Table 3, we distinguish different-sex and same-sex marriage and cohabitation. For different-sex partnerships, the effects of marriage and cohabitation are similar to those presented in panel d. For same-sex male partnerships, the wellbeing effects of marriage are substantially larger than those of cohabitation. Results for same-sex female partnerships are the opposite: that is, the well-being effects of cohabitation are substantially larger than those of marriage.

All in all, we conclude that partnership has a positive effect on subjective well-being and that this positive effect is statistically identical for same-sex and different-sex couples. Given the significant effect of marital partnership during the short survey period of five years, our results support the idea that the well-being benefits manifest in the short term, as the crisis model (Booth and Amato 1991; Pearlin 2009) and adaptation theory (Diener et al. 2006; Lucas et al. 2003) would suggest.

\section{Reverse Causality}

In the analysis of the effects of partnership dynamics on well-being, there is a possibility of selectivity or reverse causality, or both. With the linear fixed-effects 
model, we remove selectivity due to individual-specific unobserved heterogeneity related to both partnership and happiness. However, the linear fixed-effects model does not account for possible reverse causality - that is, the possibility that an individual whose happiness increases is more likely to find a partner. A person who becomes happier and more satisfied with his or her life may appear more confident and be more willing to socialize, making the person more attractive and approachable in the partnership market. Similarly, a person who experiences depression may have difficulty finding a partner (Sandberg-Thoma and Kamp Dush 2014).

To investigate whether reverse causality is an issue, we study whether single people are more likely to be partnered later on, as their happiness changes over time because of some shock. We estimate a fixed-effects model in which the dependent variable is whether an individual is partnered, and the independent variables are happiness in an earlier period and the same covariates as before. If reverse causality existed, we would expect that a higher level of happiness makes partnership formation later on more likely. We use different lags for happiness to allow for effects that materialize quickly or more slowly.

Table 4 displays the relevant parameter estimates of lagged happiness. Row a shows that a positive shock to happiness of an individual who was single does not improve his or her probability to enter a partnership one year later. Rows b-d present that also after two, three, or four years, there is no effect. None of the results are sizable or significant except the coefficient in row c for women. Although significant at $5 \%$ significance level, the magnitude of $1 \%$ is still negligible. From this, we conclude that reverse causality from happiness to future partnership dynamics is not an issue.

\section{Symmetry}

Partnership formation and partnership disruption may have different effects on subjective well-being both in sign and magnitude. Therefore, it is interesting to distinguish between entering a partnership and ending it and then to test whether their effects are symmetric. We introduce a single to partnered dummy variable with value of 1 in case of partnership formation and 0 otherwise. Likewise, the partnered to single dummy variable is 1 in case of partnership dissolution and 0 otherwise.

Table 4 Parameter estimates of the effects of subjective well-being on partnership: Individual fixed effects

\begin{tabular}{|c|c|c|c|c|}
\hline & \multicolumn{4}{|c|}{ Partnered $_{t}$} \\
\hline & Males & & Females & \\
\hline a. Happiness H $_{t-1}$ & -0.002 & $(0.005)$ & -0.000 & $(0.003)$ \\
\hline b. Happiness H $_{t-2}$ & -0.003 & $(0.006)$ & 0.002 & $(0.004)$ \\
\hline c. Happiness H $_{t-3}$ & 0.004 & $(0.007)$ & $-0.010^{*}$ & $(0.004)$ \\
\hline d. Happiness $t_{t-4}$ & 0.004 & $(0.009)$ & -0.007 & $(0.006)$ \\
\hline
\end{tabular}

Note: Standard errors are shown in parentheses. Covariates and a constant are included in every model but are not shown for parsimony.

$* p<.05$ 
Panel a of Table 5 presents seemingly asymmetric effects during partnership formation and during partnership dissolution. The first term, single to partnered, refers to the effect when a partnership forms; the second term, partnered to single, refers to the effect when a partnership dissolves. In both columns, partnership formation and disruption have opposite effects on the subjective well-being for both men and women. For example, males who transition from singlehood to partnership experience an average increase in well-being of 0.18. If they break up and become single, they face a decrease in well-being of 0.30 . To formally check whether the effects are identical in magnitude during partnership formation and disruption, we conduct the pair symmetry test with the null hypothesis such that the absolute values of the coefficients of the two transition variables are equal. The $p$ value of the test indicates that we cannot reject that the effects are symmetric.

Partnership is heterogeneous in the sense that it includes informal cohabitation and formal marriage. The subjective well-being derived from cohabitation and marriage is likely to be different. Thus, we further investigate the symmetries of transitions among marriage, cohabitation, and singlehood. Panel b of Table 5 displays the effects on subjective well-being of several types of partnership dynamics. For example, entering marriage does not seem to raise subjective well-being for cohabiting couples, whereas going from marriage to cohabitation significantly reduces men's happiness but does not affect women's happiness. ${ }^{10}$ Marriage provides a tighter, more socially recognized and enforceable contract than cohabitation, and this seems to be the case especially for males. Nevertheless, for these more elaborate dynamics among singlehood, cohabitation, and marriage, although the symmetries still hold, most of the estimates are insignificant. This may be due to the small number of observations in each transition (see Table 2). The estimation of the partnership dynamics also provides evidence for the short-term crisis model or adjustment theory. During partnership formation, subjective well-being improves quickly; during partnership dissolution, subjective well-being is harmed immediately.

\section{Age Cohort Differences}

Marital partnership may have different meanings for younger and older individuals. For instance, younger adults usually view cohabitation as a trial marriage, whereas older individuals may think of cohabitation as a long-term substitute for marriage (Brown et al. 2012; King and Scott 2005; Vespa 2012; Wright and Brown 2017).

To investigate potential heterogeneity in the effects of partnership on well-being, we test for differences by age. Kohn and Averett (2014b) distinguished individuals under 45 and over 45 and indeed found different relationship effects for the two subsamples. Following their idea, we divide the sample into two age cohorts: people born before 1962 (46 years old in the first wave of the survey in 2008) and after 1962. The relevant parameter estimates are displayed in Table 6. Panel a shows that partnership increases happiness for men born before 1962 but not for women in the same age cohort. Both men and women in the older cohort obtain larger well-being gains from marriage than from cohabitation. Panel $b$ displays that partnership exerts a positive influence in the younger cohort, and this is true for both

\footnotetext{
${ }^{10}$ Interpreting these parameter estimates should be cautious because data limitations require that we ignore partnership transitions within a year.
} 
Table 5 Parameter estimates of the effects of partnership on subjective well-being: Asymmetry of partnership formation and dissolution

\begin{tabular}{|c|c|c|c|c|}
\hline & Males & & Females & \\
\hline \multicolumn{5}{|l|}{ a. Partnership } \\
\hline Single to partnered $\left(\beta_{s p}\right)$ & $0.18^{\dagger}$ & $(0.09)$ & 0.17 & $(0.10)$ \\
\hline Partnered to single $\left(\beta_{p s}\right)$ & $-0.30 * *$ & $(0.09)$ & $-0.29 * *$ & $(0.08)$ \\
\hline$p$ value $\left(\beta_{p s}=-\beta_{s p}\right)$ & .339 & & .351 & \\
\hline \multicolumn{5}{|l|}{ b. Marriage and Cohabitation Transitions } \\
\hline Single to married $\left(\beta_{s m}\right)$ & 0.17 & $(0.16)$ & 0.28 & $(0.20)$ \\
\hline Married to single $\left(\beta_{m s}\right)$ & 0.25 & $(0.15)$ & -0.00 & $(0.13)$ \\
\hline$p$ value $\left(\beta_{s m}=\beta_{m s}\right)$ & .722 & & .249 & \\
\hline Single to cohabiting $\left(\beta_{s c}\right)$ & 0.06 & $(0.11)$ & 0.05 & $(0.12)$ \\
\hline Cohabiting to single $\left(\beta_{c s}\right)$ & $-0.18^{\dagger}$ & $(0.10)$ & -0.14 & $(0.09)$ \\
\hline$p$ value $\left(\beta_{c s}=-\beta_{c s}\right)$ & .418 & & .561 & \\
\hline Cohabiting to married $\left(\beta_{\mathrm{cm}}\right)$ & 0.06 & $(0.10)$ & 0.08 & $(0.09)$ \\
\hline Married to cohabiting $\left(\beta_{m c}\right)$ & $-0.31 *$ & $(0.15)$ & -0.02 & $(0.11)$ \\
\hline$p$ value $\left(\beta_{c m}=-\beta_{m c}\right)$ & .152 & & .660 & \\
\hline$p$ value $\left(\beta_{s m}-\beta_{m s}=\beta_{s c}+\beta_{c s}=\beta_{c m}+\beta_{m c}=0\right)$ & .429 & & .599 & \\
\hline
\end{tabular}

Notes: Column 1 contains 12,955 observations of 3,088 men; column 2 contains 14,824 observations of 3,617 women. Standard errors are shown in parentheses.

$\dagger p<.10 ; * p<.05 ; * * p<.01$

Table 6 Parameter estimates of the effects of partnership on subjective well-being by age cohort

\begin{tabular}{|c|c|c|c|c|}
\hline & Males & & Females & \\
\hline \multicolumn{5}{|l|}{ a. Born Before 1962} \\
\hline Partner & $0.28 *$ & $(0.12)$ & 0.17 & $(0.15)$ \\
\hline \multicolumn{5}{|l|}{ Marriage vs. cohabitation } \\
\hline Marriage $\left(\beta_{m}\right)$ & $0.36 * *$ & $(0.12)$ & $0.31 *$ & $(0.16)$ \\
\hline Cohabitation $\left(\beta_{c}\right)$ & 0.13 & $(0.14)$ & -0.10 & $(0.17)$ \\
\hline$p$ value $\left(\beta_{m}=\beta_{c}\right)$ & $.044 *$ & & $.000 * *$ & \\
\hline \multicolumn{5}{|l|}{ b. Born in 1962 or Later } \\
\hline Partner & $0.25 * *$ & $(0.09)$ & $0.30 * *$ & $(0.08)$ \\
\hline \multicolumn{5}{|l|}{ Marriage vs. cohabitation } \\
\hline Marriage & $0.30 * *$ & $(0.11)$ & $0.37 * *$ & $(0.10)$ \\
\hline Cohabitation & $0.23 * *$ & $(0.09)$ & $0.28 * *$ & $(0.08)$ \\
\hline$p$ value $\left(\beta_{m}=\beta_{c}\right)$ & .515 & & .313 & \\
\hline
\end{tabular}

Notes: Panel a contains 15,395 observations with 1,704 men and 1,773 women; panel b contains 12,384 observations with 1,385 men and 1,845 women. Standard errors are shown in parentheses.

$* p<.05 ; * * p<.01$ 
marriage and cohabitation. For the younger cohort, the happiness benefits from marriage are larger than those from cohabitation, but the difference is not statistically significant.

These findings raise an interesting question. Why does cohabitation benefit the younger age cohort but not the older one? We speculate that older adults may prefer to protect the wealth they have accumulated over their lifetime rather than pool the resources with their partner (Brown et al. 2012), and cohabitation allows them to retain financial and economic autonomy that would not be possible in marriage (Brown et al. 2016; Chevan 1996; Hatch 1995). Furthermore, older adults, especially older women, may be less willing to provide caregiving to a partner at a later stage of their life, and cohabitation does not explicitly encourage this kind of responsibility as marriage does (Talbott 1998). Another possible explanation is that for people born before 1962, cohabitation was still not widely accepted when they entered the partnership market. The social attitude regarding cohabitation may also have influenced their individual attitudes. Although they later chose to cohabit, they still did not regard cohabitation as similar to marriage. On the contrary, when individuals in the younger age cohort entered a partnership, societal attitudes regarding cohabitation were quite tolerant. Currently, cohabitation is a more popular partnership choice than marriage.

\section{Conclusions}

Many studies have found positive well-being effects of a partnership, for which there are various explanations. Partnered individuals may gain from production complementarities, division of labor or consumption, and investment complementarities. Couples may also benefit from economies of scale by pooling resources, jointly consuming public goods and investing in children, and sharing leisure activities. A partnership may strengthen and expand social relationships. Finally, a partnership may introduce social control and mutual supervision.

We analyze Dutch panel data to investigate whether partnership has a causal effect on subjective well-being, finding that this is indeed the case. We do not find evidence for reverse causality, which occurs if a positive shock to one's well-being induces partnership formation. As in a few previous studies, we find that well-being gains of marriage are larger than those of cohabitation, a result that may be related to different investment levels of tangible and intangible capital. We also find that the well-being effects of partnership formation and disruption are symmetric. Because our panel covers a five-year period, this finding supports the prediction based on crisis model and adaptation theory that the wellbeing effects of marital partnership transitions manifest in the short term rather than that they need a long time to accumulate. Furthermore, we find that marriage improves wellbeing for both younger and older cohorts, whereas cohabitation benefits only the younger cohort. This finding may be due to the weaker desire of pooling economic resources and lower willingness of caregiving for older cohabitants. Alternatively, it could be the result of different social acceptance of cohabitation when older individuals initially entered the partnership market a long time ago; although they later on chose to cohabit, perhaps older individuals still do not regard cohabitation as similar to marriage.

We contribute to the literature by studying partnership dynamics, investigating reverse causality and establishing cohort-specific differences in well-being effects, but our main contribution is illuminating well-being effects of same-sex partnerships. We find that these effects are similar to those of different-sex partnerships. This may 
seem surprising because of possible discrimination against sexual minorities after their sexual orientation is disclosed. Perhaps thanks to the effective implementation of education and policy on marriage equality and respect for sexual minorities, this prejudice against sexual minorities does not prevail in the Netherlands. Although same-sex and different-sex partnerships overall have similar effects on well-being, we do find gender differences in the well-being effects of same-sex partnerships. Females are happier cohabiting, whereas marriage has a stronger well-being effect on males. We can only speculate about the reasons for this difference given that the literature on the well-being effects of different types of partnerships for sexual minorities is limited. Perhaps marriage provides a tighter, more socially recognized and enforceable contract than cohabitation, especially for male same-sex partnerships. For female same-sex partnerships, this seems to be less of an issue.

We are confronted with a few difficulties in the current study. First, the analysis is based on a short panel, so we are unable to examine whether the well-being effects of partnership dynamics will persist in the long term. The crisis model argues that the effects are temporary, whereas the resource model suggests that the effects need a long time to materialize. To investigate which of the models is more realistic, a longer panel would be more helpful. Second, to analyze heterogeneity of sexual orientation in wellbeing effects of partnership dynamics in more detail, a larger data set is needed. The number of partnership transitions and the size of same-sex sample are still relatively small in our data. Because of these limitations, our parameter estimates for same-sex partnerships are imprecise. Third, although we include a number of time-varying covariates and apply the fixed-effects model to account for time-invariant unobservable characteristics, we cannot completely resolve the concern of the possible time-varying confounding unobservable factors. If panel data contain information on the nature and magnitude of exogenous shocks to partnership market, we would be able to exploit such a shock to draw a more compelling causal conclusion.

Acknowledgments We are grateful to CentERdata for making the LISS data available for this article. We also thank participants at ESPE 2016, EALE 2016, and a CEP well-being seminar as well as reviewers for their comments on a previous version of this article.

Open Access This article is distributed under the terms of the Creative Commons Attribution 4.0 International License (http://creativecommons.org/licenses/by/4.0/), which permits unrestricted use, distribution, and reproduction in any medium, provided you give appropriate credit to the original author(s) and the source, provide a link to the Creative Commons license, and indicate if changes were made.

\section{References}

Acock, A. C., \& Demo, D. H. (1994). Family diversity and well-being. Thousand Oaks, CA: Sage.

Ali, M. M., \& Ajilore, O. (2011). Can marriage reduce risky health behavior for African-Americans? Journal of Family and Economic Issues, 32, 191-203.

Amato, P. R. (2000). The consequences of divorce for adults and children. Journal of Marriage and the Family, 62, 1269-1287.

Andersson, G., Noack, T., Seierstad, A., \& Weedon-Fekjaer, H. (2006). The demographics of same-sex marriages in Norway and Sweden. Demography, 43, 79-98.

Anusic, I., Yap, S. C. Y., \& Lucas, R. E. (2014). Testing set-point theory in a Swiss national sample: Reaction and adaptation to major life events. Social Indicators Research, 119, 1265-1288. 
Avellar, S., \& Smock, P. J. (2005). The economic consequences of the dissolution of cohabiting unions. Journal of Marriage and Family, 67, 315-327.

Averett, S. L., Argys, L. M., \& Sorkin, J. (2013). In sickness and in health: An examination of relationship status and health using data from the Canadian National Public Health Survey. Review of Economics of the Household, 11, 599-633.

Badgett, M. V. L. (1995). The wage effects of sexual orientation discrimination. Industrial and Labor Relations Review, 48, 726-739.

Bakker, F., de Graaf, H., de Haas, S., Kedde, H., Kruijer, H., \& Wijsen, C. (2009). Sexual health in the Netherlands 2009. Utrecht, the Netherlands: Rutgers Nisso Groep.

Becker, G. S. (1974). A theory of marriage: Part II. Journal of Political Economy, 82(2, Part 2), S11-S26.

Becker, G. S. (1981). A treatise on the family. Cambridge, MA: Harvard University Press.

Berg, N., \& Lien, D. (2002). Measuring the effect of sexual orientation on income: Evidence of discrimination? Contemporary Economic Policy, 20, 394414.

Blekesaune, M. (2008). Partnership transitions and mental distress: Investigating temporal order. Journal of Marriage and Family, 70, 879-890.

Blundell, R., \& Bond, S. (1998). Initial conditions and moment restrictions in dynamic panel data models. Journal of Econometrics, 87, 115-143.

Booth, A., \& Amato, P. (1991). Divorce and psychological stress. Journal of Health and Social Behavior, 32, 396-407.

Brown, S. L., Bulanda, J. R., \& Lee, G. R. (2005). The significance of nonmarital cohabitation: Marital status and mental health benefits among middle-aged and older adults. Journals of Gerontology, Series B: Psychological Sciences and Social Sciences, 60(Special Issue 1), S21-S29.

Brown, S. L., Bulanda, J. R., \& Lee, G. R. (2012). Transitions into and out of cohabitation in later life. Journal of Marriage and Family, 74, 774-793.

Brown, S. L., Lee, G. R., \& Bulanda, J. R. (2006). Cohabitation among older adults: A national portrait. Journals of Gerontology, Series B: Psychological Sciences and Social Sciences, 61, S71-S79.

Brown, S. L., \& Lin, I.-F. (2012). The gray divorce revolution: Rising divorce among middle-aged and older adults, 1990-2010. Journals of Gerontology, Series B: Psychological Sciences and Social Sciences, 67, 731-741.

Brown, S. L., Lin, I.-F., Hammersmith, A. M., \& Wright, M. R. (2016). Later life marital dissolution and repartnership status: A national portrait. Journals of Gerontology, Series B: Psychological Sciences and Social Sciences. Advance online publication. https://doi.org/10.1093/geronb/gbw051

Brown, S. L., \& Shinohara, S. K. (2013). Dating relationships in older adulthood: A national portrait. Journal of Marriage and Family, 75, 1194-1202.

Calasanti, T., \& Kiecolt, K. J. (2007). Diversity among late-life couples. Generations, 31(3), 10-17.

Carpenter, C. S. (2007). Revisiting the income penalty for behaviorally gay men: Evidence from NHANES III. Labour Economics, 14, 25-34.

Carr, D., \& Springer, K. W. (2010). Advances in families and health research in the 21st century. Journal of Marriage and Family, 72, 743-761.

Chapman, B., \& Guven, C. (2016). Revisiting the relationship between marriage and wellbeing: Does marriage quality matter? Journal of Happiness Studies, 17, 533-551.

Chevan, A. (1996). As cheaply as one: Cohabitation in the older population. Journal of Marriage and the Family, 58, 656-667.

Clain, S. H., \& Leppel, K. (2001). An investigation into sexual orientation discrimination as an explanation for wage differences. Applied Economics, 33, 37-47.

Clark, A. E., \& Etilé, F. (2006). Don't give up on me baby: Spousal correlation in smoking behaviour. Journal of Health Economics, 25, 958-978.

Clark, A. E., \& Etilé, F. (2011). Happy house: Spousal weight and individual well-being. Journal of Health Economics, 30, 1124-1136.

Cooney, T. M., \& Dunne, K. (2001). Intimate relationships in later life: Current realities, future prospects. Journal of Family Issues, 22, 838-858.

Diener, E., Lucas, R. E., \& Scollon, C. N. (2006). Beyond the hedonic treadmill: Revising the adaptation theory of well-being. American Psychologist, 61, 305-314.

Diener, E., Scollon, C. N., \& Lucas, R. E. (2009). The evolving concept of subjective well-being: The multifaceted nature of happiness. In E. Diener (Ed.), Assessing well-being: The collected works of Ed Diener (Social Indicators Research Series Vol. 39, pp. 67-100). Dordrecht, the Netherlands: Springer.

Diener, E., \& Suh, M. E. (1997). Subjective well-being and age: An international analysis. In K. W. Schaie \& M. P. Lawton (Eds.), Annual review of gerontology and geriatrics: Focus on emotion and adult development (Vol. 17, pp. 304-324). New York, NY: Springer. 
Duncan, G. J., Wilkerson, B., \& England, P. (2006). Cleaning up their act: The effects of marriage and cohabitation on licit and illicit drug use. Demography, 43, 691-710.

Elmslie, B., \& Tebaldi, E. (2007). Sexual orientation and labor market discrimination. Journal of Labor Research, 28, 436-453.

European Commission. (2015). Special eurobarometer 437: Discrimination in the EU in 2015. Brussels, Belgium: Directorate-General for Communication, European Union.

Ferreri Carbonell, A., \& Frijters, P. (2004). How important is methodology for the estimates of the determinants of happiness? Economic Journal, 114, 641-659.

Fingerhut, A. W., \& Maisel, N. C. (2010). Relationship formalization and individual and relationship wellbeing among same-sex couples. Journal of Social and Personal Relationships, 27, 956-969.

Finkel, E. J., Hui, C. M., Carswell, K. L., \& Larson, G. M. (2014). The suffocation of marriage: Climbing Mount Maslow without enough oxygen. Psychological Inquiry, 25, 1-41.

Fleming, C. B., White, H. R., \& Catalano, R. F. (2010). Romantic relationships and substance use in early adulthood: An examination of the influences of relationship type, partner substance use, and relationship quality. Journal of Health and Social Behavior, 51, 153-167.

Gorman, B. K., Denney, J. T., Dowdy, H., \& Medeiros, R. A. (2015). A new piece of the puzzle: Sexual orientation, gender, and physical health status. Demography, 52, 1357-1382.

Gove, W. R., \& Shin, H.-C. (1989). The psychological well-being of divorced and widowed men and women: An empirical analysis. Journal of Family Issues, 10, 122-144.

Graham, C., Higuera, L., \& Lora, E. (2011). Which health conditions cause the most unhappiness? Health Economics, 20, 1431-1447.

Hansen, T., Moum, T., \& Shapiro, A. (2007). Relational and individual well-being among cohabitors and married individuals in midlife: Recent trends from Norway. Journal of Family Issues, 28, 910-933.

Hatch, R. (1995). Aging and cohabitation. New York, NY: Garland.

Hatzenbuehler, M. L., McLaughlin, K. A., Keyes, K. M., \& Hasin, D. S. (2010). The impact of institutional discrimination on psychiatric disorders in lesbian, gay, and bisexual populations: A prospective study. American Journal of Public Health, 100, 452-459.

Huebner, D. M., Rebchook, G. M., \& Kegeles, S. M. (2004). Experiences of harassment, discrimination, and physical violence among young gay and bisexual men. American Journal of Public Health, 94, 12001203.

Johnson, D. R., \& Wu, J. (2002). An empirical test of crisis, social selection, and role explanations of the relationship between marital disruption and psychological distress: A pooled time-series analysis of fourwave panel data. Journal of Marriage and Family, 64, 211-224.

Kalmijn, M. (2017). The ambiguous link between marriage and health: A dynamic reanalysis of loss and gain effects. Social Forces, 95, 1607-1636.

Kamp Dush, C. M. (2013). Marital and cohabitation dissolution and parental depressive symptoms in fragile families. Journal of Marriage and Family, 75, 91-109.

Kamp Dush, C. M., \& Amato, P. R. (2005). Consequences of relationship status and quality for subjective well-being. Journal of Social and Personal Relationships, 22, 607-627.

Kennedy, S., \& Ruggles, S. (2014). Breaking up is hard to count: The rise of divorce in the United States, 1980-2010. Demography, 51, 587-598.

Killewald, A. (2013). A reconsideration of the fatherhood premium: Marriage, coresidence, biology, and fathers' wages. American Sociological Review, 78, 96-116.

Kim, H. K., \& McKenry, P. C. (2002). The relationship between marriage and psychological well-being: A longitudinal analysis. Journal of Family Issues, 23, 885-911.

King, V., \& Scott, M. E. (2005). A comparison of cohabiting relationships among older and younger adults. Journal of Marriage and Family, 67, 271-285.

Kohn, J. L., \& Averett, S. L. (2014a). Can't we just live together? New evidence on the effect of relationship status on health. Journal of Family and Economic Issues, 35, 295-312.

Kohn, J. L., \& Averett, S. L. (2014b). The effect of relationship status on health with dynamic health and persistent relationships. Journal of Health Economics, 36, 69-83.

Kurdek, L. A. (1991). The relations between reported well-being and divorce history, availability of a proximate adult, and gender. Journal of Marriage and the Family, 53, 71-78.

Latten, J. J., \& Mulder, C. H. (2013). Partner relationships in the Netherlands: New manifestations of the Second Demographic Transition. Genus, 69(3), 103-121.

Lesthaeghe, R. J. (2007). Second demographic transition. In G. Ritzer (Ed.), The Blackwell encyclopedia of sociology. https://doi.org/10.1002/9781405165518.wbeoss059.pub2

Lesthaeghe, R., \& Surkyn, J. (1988). Cultural dynamics and economic theories of fertility change. Population and Development Review, 14, 1-45. 
Lillard, L. A., \& Panis, C. W. (1996). Marital status and mortality: The role of health. Demography, 33, 313327.

Lucas, R. E., \& Clark, A. E. (2006). Do people really adapt to marriage? Journal of Happiness Studies, 7 , 405-426.

Lucas, R. E., Clark, A. E., Georgellis, Y., \& Diener, E. (2003). Reexamining adaptation and the set point model of happiness: Reactions to changes in marital status. Journal of Personality and Social Psychology, 84, 527-539.

Lundberg, S., \& Pollak, R. A. (2015). The evolving role of marriage: 1950-2010. Future of Children, 25(2), 29-50.

Mastekaasa, A. (1995). Age variations in the suicide rates and self-reported subjective well-being of married and never married persons. Journal of Community \& Applied Social Psychology, 5, 21-39.

Mays, V. M., \& Cochran, S. D. (2001). Mental health correlates of perceived discrimination among lesbian, gay, and bisexual adults in the United States. American Journal of Public Health, 91, 1869-1876.

McCabe, S. E., Bostwick, W. B., Hughes, T. L., West, B. T., \& Boyd, C. J. (2010). The relationship between discrimination and substance use disorders among lesbian, gay, and bisexual adults in the United States. American Journal of Public Health, 100, 1946-1952.

Mernitz, S. E., \& Kamp Dush, C. (2016). Emotional health across the transition to first and second unions among emerging adults. Journal of Family Psychology, 30, 233-244.

Meyer, I. H. (2003). Prejudice, social stress, and mental health in lesbian, gay, and bisexual populations: Conceptual issues and research evidence. Psychological Bulletin, 129, 674-697.

Michael, R. T. (2004). Sexual capital: An extension of Grossman's concept of health capital. Journal of Health Economics, 23, 643-652.

Monden, C. W., van Lenthe, F., de Graaf, N. D., \& Kraaykamp, G. (2003). Partner's and own education: Does who you live with matter for self-assessed health, smoking and excessive alcohol consumption? Social Science \& Medicine, 57, 1901-1912.

Musick, K., \& Bumpass, L. (2012). Reexamining the case for marriage: Union formation and changes in wellbeing. Journal of Marriage and Family, 74, 1-18.

Noack, T., Seierstad, A., \& Weedon-Fekjær, H. (2005). A demographic analysis of registered partnerships (legal same-sex unions): The case of Norway. European Journal of Population/Revue européenne de Démographie, 21, 89-109.

Nock, S. L. (1995). A comparison of marriages and cohabiting relationships. Journal of Family Issues, 16, 53-76.

Patacchini, E., Ragusa, G., \& Zenou, Y. (2015). Unexplored dimensions of discrimination in Europe: Homosexuality and physical appearance. Journal of Population Economics, 28, 1045-1073.

Pearlin, L. I. (1999). Stress and mental health: A conceptual overview. In A. V. Horwitz \& T. L. Scheid (Eds.), A handbook for the study of mental health: Social contexts, theories, and systems (pp. 161-175). New York, NY: Cambridge University Press.

Pearlin, L. I. (2009). The life course and the stress process: Some conceptual comparisons. Journals of Gerontology, Series B: Psychological Sciences and Social Sciences, 65, 207-215.

Plug, E., \& Berkhout, P. (2004). Effects of sexual preferences on earnings in the Netherlands. Journal of Population Economics, 17, 117-131.

Plug, E., Webbink, D., \& Martin, N. (2014). Sexual orientation, prejudice, and segregation. Journal of Labor Economics, 32, 123-159.

Rhoades, G. K., Kamp Dush, C. M., Atkins, D. C., Stanley, S. M., \& Markman, H. J. (2011). Breaking up is hard to do: The impact of unmarried relationship dissolution on mental health and life satisfaction. Journal of Family Psychology, 25, 366-374.

Riggle, E. D., Rostosky, S. S., \& Horne, S. G. (2010). Psychological distress, well-being, and legal recognition in same-sex couple relationships. Journal of Family Psychology, 24, 82-86.

Ross, C. E. (1995). Reconceptualizing marital status as a continuum of social attachment. Journal of Marriage and the Family, 57, 129-140.

Rostosky, S. S., Riggle, E. D., Gray, B. E., \& Hatton, R. L. (2007). Minority stress experiences in committed same-sex couple relationships. Professional Psychology: Research and Practice, 38, 392-400.

Rusbult, C. E. (1980). Commitment and satisfaction in romantic associations: A test of the investment model. Journal of Experimental Social Psychology, 16, 172-186.

Sandberg-Thoma, S. E., \& Kamp Dush, C. M. (2014). Casual sexual relationships and mental health in adolescence and emerging adulthood. Journal of Sex Research, 51, 121-130.

Sandfort, T. G., Bakker, F., Schellevis, F. G., \& Vanwesenbeeck, I. (2006). Sexual orientation and mental and physical health status: Findings from a Dutch population survey. American Journal of Public Health, 96, 1119-1125. 
Sassler, S. (2010). Partnering across the life course: Sex, relationships, and mate selection. Journal of Marriage and Family, 72, 557-575.

Simon, R. W. (2002). Revisiting the relationships among gender, marital status, and mental health. American Journal of Sociology, 107, 1065-1096.

Simpson, J. A. (1987). The dissolution of romantic relationships: Factors involved in relationship stability and emotional distress. Journal of Personality and Social Psychology, 53, 683-692.

Soons, J. P., \& Kalmijn, M. (2009). Is marriage more than cohabitation? Well-being differences in 30 European countries. Journal of Marriage and Family, 71, 1141-1157.

Soons, J. P., Liefbroer, A. C., \& Kalmijn, M. (2009). The long-term consequences of relationship formation for subjective well-being. Journal of Marriage and Family, 71, 1254-1270.

Stanley, S. M., Rhoades, G. K., \& Markman, H. J. (2006). Sliding versus deciding: Inertia and the premarital cohabitation effect. Family Relations, 55, 499-509.

Stanley, S. M., Whitton, S. W., \& Markman, H. J. (2004). Maybe I do: Interpersonal commitment and premarital or nonmarital cohabitation. Journal of Family Issues, 25, 496-519.

Statistics Netherlands. (n.d.). StatLine [Database]. Available from http://statline.cbs.nl/Statweb/?LA=en

Stevenson, B., \& Wolfers, J. (2007). Marriage and divorce: Changes and their driving forces. Journal of Economic Perspectives, 21(2), 27-52.

Stroebe, M., Schut, H., \& Stroebe, W. (2007). Health outcomes of bereavement. Lancet, 370, 1960-1973.

Strohschein, L., McDonough, P., Monette, G., \& Shao, Q. (2005). Marital transitions and mental health: Are there gender differences in the short-term effects of marital status change? Social Science \& Medicine, 61, 2293-2303.

Stutzer, A., \& Frey, B. S. (2006). Does marriage make people happy, or do happy people get married? Journal of Socio-Economics, 35, 326-347.

Talbott, M. M. (1998). Older widows' attitudes towards men and remarriage. Journal of Aging Studies, 12, $429-449$.

Umberson, D. (1992). Gender, marital status and the social control of health behavior. Social Science \& Medicine, 34, 907-917.

Umberson, D., \& Karas Montez, J. (2010). Social relationships and health: A flashpoint for health policy. Journal of Health and Social Behavior, 51, S54-S66.

van den Berg, G. J., \& Gupta, S. (2015). The role of marriage in the causal pathway from economic conditions early in life to mortality. Journal of Health Economics, 40, 141-158.

Vespa, J. (2012). Union formation in later life: Economic determinants of cohabitation and remarriage among older adults. Demography, 49, 1103-1125.

Waite, L. J., \& Gallagher, M. (2000). The case for marriage: Why married people are happier, healthier, and better off financially. New York, NY: Broadway Books.

Waldron, I., Hughes, M. E., \& Brooks, T. L. (1996). Marriage protection and marriage selection? Prospective evidence for reciprocal effects of marital status and health. Social Science \& Medicine, 43, 113-123.

Wheaton, B. (1990). Life transitions, role histories, and mental health. American Sociological Review, 55, 209-223.

White, J. M. (1992). Marital status and well-being in Canada: An analysis of age group variations. Journal of Family Issues, 13, 390-409.

Wight, R. G., LeBlanc, A. J., \& Badgett, M. V. L. (2013). Same-sex legal marriage and psychological wellbeing: Findings from the California Health Interview Survey. American Journal of Public Health, 103, 339-346.

Williams, K. (2003). Has the future of marriage arrived? A contemporary examination of gender, marriage, and psychological well-being. Journal of Health and Social Behavior, 44, 470-487.

Williams, K., \& Dunne-Bryant, A. (2006). Divorce and adult psychological well-being: Clarifying the role of gender and child age. Journal of Marriage and Family, 68, 1178-1196.

Williams, K., \& Umberson, D. (2004). Marital status, marital transitions, and health: A gendered life course perspective. Journal of Health and Social Behavior, 45, 81-98.

Wilson, C. M., \& Oswald, A. J. (2005). How does marriage affect physical and psychological health? A survey of the longitudinal evidence (IZA Discussion Paper No. 1619). Bonn, Germany: Institute for the Study of Labor.

Wright, M. R., \& Brown, S. L. (2017). Psychological well-being among older adults: The role of partnership status. Journal of Marriage and Family, 79, 833-849. 